\title{
Higher levels of anti-phosphorylcholine autoantibodies in early rheumatoid arthritis indicate lower risk of incident cardiovascular events
}

\author{
Sofia Ajeganova ${ }^{1,2^{*}}$ (D), Maria L. E. Andersson ${ }^{3}$, Johan Frostegård ${ }^{4}$ and Ingiäld Hafström ${ }^{1,5}$
}

\begin{abstract}
Background: The increased risk of cardiovascular events (CVE) in rheumatoid arthritis (RA) is not fully explained by traditional risk factors. Immuno-inflammatory mechanisms and autoantibodies could be involved in the pathogenesis of atherosclerotic disease. It has been suggested that anti-phosphorylcholine antibodies (anti-PC) of the IgM subclass may have atheroprotective effects. Here, we aimed to investigate the association between levels of IgM anti-PC antibodies with CVE in patients with early RA.
\end{abstract}

Methods: The study population was derived from the BARFOT early RA cohort, recruited in 1994-1999. The outcome of incident CVE (AMI, angina pectoris, coronary intervention, ischemic stroke, TIA) was tracked through the Swedish Hospital Discharge and the National Cause of Death Registries. Sera collected at inclusion and the 2-year visit were analyzed with ELISA to determine levels of anti-PC IgM. The Kaplan-Meier estimates and Cox proportional hazards regression models were used to compare CV outcome in the groups categorized by baseline median level of IgM anti-PC.

Results: In all, 653 patients with early RA, 68\% women, mean (SD) age 54.8 (14.7) years, DAS28 5.2 (1.3), 68\% seropositive, and without prevalent CVD, were included. During the follow-up of mean 11.7 years, 141 incident CVE were recorded.

Baseline IgM anti-PC above median was associated with a reduction in risk of incident CVE in patients aged below 55 years at inclusion, HR 0.360 (95\% Cl, 0.142-0.916); in males, HR 0.558 (0.325-0.958); in patients with BMl above 30 $\mathrm{kg} / \mathrm{m}^{2}$, HR 0.235 (0.065-0.842); and in those who did not achieve DAS28 remission at 1 year, HR 0.592 (0.379-0.924). The pattern of associations was confirmed in the models with AUC IgM anti-PC over 2 years.

Conclusion: Protective effects of higher levels of innate IgM anti-PC autoantibodies on CVE were detected in younger patients with RA and those at high risk of CVE: males, presence of obesity, and non-remission at 1 year.

Keywords: Phosphorylcholine autoantibodies, Innate immunity, Cardiovascular events, Rheumatoid arthritis

\footnotetext{
* Correspondence: sofia.ajeganova@ki.se

'Division of Gastroenterology and Rheumatology, Department of Medicine Huddinge, Karolinska Institutet, 17177 Stockholm, Sweden

${ }^{2}$ Department of Clinical Sciences, Rheumatology Division, Universitair Ziekenhuis Brussel, Vrije Universiteit Brussel, Brussels, Belgium

Full list of author information is available at the end of the article
} 


\section{Introduction}

The increased cardiovascular (CV) risk in rheumatoid arthritis (RA) is not fully explained by traditional risk factors and genetic markers $[1,2]$. Inflammation plays a critical role in atherothrombosis [3]. Immuno-inflammatory mechanisms and autoantibodies could be involved in the pathogenesis of atherosclerotic disease $[4,5]$. While most studies examine the risk factors of atherosclerosis and CV outcomes, studies focusing on the possible protective factors have been scarce.

Phosphorylcholine (PC), a component of phospholipids, is an important pro-inflammatory damage-associated compound, which is immunogenic if exposed as auto-antigens during stress, tissue damage, and inflammation [6, 7]. Anti-phosphorylcholine autoantibodies (anti-PC) have a role in maintaining the homeostasis of the immune system [8]. These autoantibodies serve "housekeeping" and could enhance clearance of damaged apoptotic cells, senescent IL-17+ T-cells, oxidized or otherwise modified lipoproteins, and induce intracellular blockade of inflammatory signaling cascades $[7,9]$.

Anti-PC of IgM subclass have atheroprotective effects and may play a role in the formation and stabilization of atherosclerotic plaque $[8,10]$. Low levels of IgM anti-PC autoantibodies have been shown in association with increased risk of acute myocardial infarction and ischemic stroke and could predict CV disease (CVD) [11-13], which could be partly mediated by a fast carotid intimamedia thickness (cIMT) progression [14]. Lower levels of IgM anti-PC autoantibodies have been reported in patients with RA who developed CVD and in SLE patients with carotid atherosclerotic plaques $[15,16]$. In contrast, high levels of IgM anti-PC may be protective and associate with a reduced rate of atherosclerosis progression $[17,18]$.

Whether the effects of innate immunity are dependent on the individual risk characteristics is unknown. If protective effects of anti-PC autoantibodies differ in the patient settings, this might explain that some studies observed an association between levels of anti-PC and risk of CV events (CVE) [19], while others did not [20]. Indeed, an unfavorable effect of low anti-PC on cIMT progression and risk of CVE has been evident in men, but not in women [14]. Further, the relation between high levels of IgM anti-PC and a decreased rate of cIMT progression has been observed among patients with hypertension [21]. Association between IgM anti-PC autoantibodies and pro-atherogenic $\mathrm{T}$ cell subsets in SLE has been shown in patients with high triglyceride or low HDL levels, but not in those with a normal lipid profile [22].

We hence hypothesized that the association between innate immunity and atherosclerosis and, therefore, benefits of $\mathrm{CV}$ risk reduction in relation to high levels of
IgM anti-PC could be different depending on the $\mathrm{CV}$ risk level of the studied population. The aim of the present analysis was to investigate the association between IgM anti-PC autoantibodies with $\mathrm{CV}$ morbidity in a large cohort of patients with early RA within the groups defined by demographics and $\mathrm{CV}$ risk characteristics.

\section{Patients and methods}

\section{Patients and outcome assessment}

The study population was derived from the prospective observational BARFOT (Better Anti-Rheumatic PharmacO Therapy) cohort from secondary care in southern Sweden with newly diagnosed early (symptom duration $\leq 1$ year) RA according to the ACR 1987 criteria [23]. Patients were enrolled between 1993 and 1999. Treatment was started and adjusted during follow-up by the treating rheumatologist in accordance with the current recommendations. For a further cohort description, see elsewhere [24].

The study participants provided written informed consent. The study was approved by the local ethics committees, EPN Stockholm 2008/840-31 and 2011/ $381-31 / 4$, and was performed in accordance with the Declaration of Helsinki.

\section{Data collection}

Of 780 eligible patients aged $>18$ years without prevalent $\mathrm{CV}$ event prior to inclusion, 653 patients with available blood samples at baseline for analysis of anti-PC autoantibodies were included in this study. Of these, $523 \mathrm{had}$ anti-PC antibodies measured both at baseline and follow-up at 2 years. Baseline characteristics of the patients with available blood samples and those without were similar as to age, sex, main disease characteristics, and $\mathrm{CV}$ risk factors.

Demographics, body mass index (BMI), laboratory data, and information on DMARDs were obtained from the BARFOT database. The following $\mathrm{CV}$ risk factors were registered at inclusion: smoking history, selfreported history or medication prescription for hypertension, diabetes mellitus, and hyperlipidemia.

RA disease activity was calculated using the Disease Activity Score for 28 joints (DAS28) with ESR [25]. Disease remission was defined as DAS28 $<2.6$ [26]. Functional status was self-assessed by the validated Swedish version of the Stanford Health Assessment Questionnaire (HAQ) [27].

Antibodies to cyclic citrullinated peptides (anti-CCP) were detected using the enzyme-linked immunosorbent assay (ELISA) CCP2 test (Euro-Diagnostica, Malmö, Sweden), and a level > $25 \mathrm{IU} / \mathrm{ml}$ was regarded as positive. IgM RF was measured by agglutination test (Serodia, Fujirebio, Tokyo, Japan), and a level $>20$ units/ 
$\mathrm{ml}$ was defined as positive. Seropositivity was defined by the presence of RF and/or anti-CCP. IgM anti-PC autoantibodies were determined in serum samples collected at baseline and at 2 years using ELISA (Athera CVDefine kit, Athera Biotechnologies AB, Stockholm, Sweden) in accordance with the manufacturer's instructions [12].

\section{Outcome assessment}

The outcome was CVE such as fatal or non-fatal myocardial infarction, angina pectoris, coronary intervention, ischemic stroke, and transient ischemic attack (TIA). CV morbidity data were identified through the Swedish Hospital Discharge Registry from 1987 and the National Cause of Death Registries through 2010. Patients contributed at-risk time from the date of entry into the cohort. Censoring date occurred at the date of first-ever incident $\mathrm{CV}$ event, or death, or censoring date of December 2010, whichever occurred first.

\section{Statistical methods}

Descriptive statistics are reported as means (SD) or medians (IQR), as suitable, for continuous variables, and percentages for categorical variables. To compare medians between the groups, a Mann-Whitney $U$ test for independent samples was used. The area under the curve (AUC) was calculated for the measures of IgM anti-PC assessed at inclusion and after 2 years.

The incidence $\mathrm{CV}$ rates with the $95 \%$ confidence interval (CI) for a Poisson count were presented as events per 100 person-years at risk. The clinically relevant cutoffs of novel IgM anti-PC autoantibodies are not established. Before performing analysis, based on previous results and in order to have reasonably large groups for survival analysis, we have chosen an arbitrary threshold at median IgM anti-PC levels for this study. Rates of event-free survival in patients in total and per group divided by median IgM anti-PC (higher IgM anti-PC levels vs. lower levels) were compared using a Kaplan-Meier analysis. Equality of time-to-event function between the groups was tested with a log-rank test. Relative hazard ratios from Cox regression models were used to estimate the effect of IgM anti-PC on the outcome in total patient population and within the groups categorized by sex, ages (above the median age of 55 years at inclusion vs. below the median age of 55 years), traditional risk factors, and disease characteristics with progressive adjustment if a $p<0.10$ : unadjusted, adjusted for age and sex, and further fully adjusted for traditional CV risk factors (BMI, smoking, hypertension, diabetes mellitus, hyperlipidemia).

Significance tests were two-tailed and conducted at the 0.05 level of significance. IBM SPSS, version 26 (SPSS Inc., Chicago, IL), was used for the analyses.

\section{Results}

Baseline characteristics of 653 included patients with early RA are summarized in Table 1 . Their mean age was 55 years, $68 \%$ were women, $68 \%$ were seropositive, and the mean DAS28 was 5.2. Of all, $29 \%$ of the patients were current smokers, $15 \%$ had hypertension, and only $4 \%$ and $1 \%$ of the patients reported history or treatment for diabetes and hyperlipidemia, respectively. A good half of the patients received MTX and glucocorticoids, and only $2.4 \%$ of the patients could receive biologic DMARDs in the first 2 years. DAS28 remission was achieved in $36 \%$ of the cohort at 1 year and in $40 \%$ at the 2-year follow-up.

Median (IQR) IgM anti-PC decreased from baseline levels of $60.9(36.4-94.9) \mathrm{U} / \mathrm{ml}$ to $56.0(32.3-84.2)$ at 2 years, $p<0.001$. The baseline and 2 -year follow-up levels of IgM anti-PC were lower in patients with $\mathrm{CV}$ outcome than in those without, $p=0.020$ and $p=0.012$, respectively. Baseline median IgM anti-PC levels were also statistically significantly lower in patients older than 55

Table 1 Characteristics in 653 patients with rheumatoid arthritis

\begin{tabular}{|c|c|}
\hline \multicolumn{2}{|l|}{ Characteristics at baseline } \\
\hline Age, years & $54.8(14.7)$ \\
\hline Women, \% & 68 \\
\hline $\mathrm{BMI}, \mathrm{kg} / \mathrm{m}^{2}$ & $25.5(5.1)$ \\
\hline Smoking current, \% & 29 \\
\hline Hypertension, \% & 15 \\
\hline Diabetes mellitus, \% & 4 \\
\hline Hyperlipidemia, \% & 1 \\
\hline Symptom duration, months & $6.3(3.2)$ \\
\hline Seropositive, \% & 68 \\
\hline DAS28 & $5.16(1.27)$ \\
\hline $\mathrm{HAQ}$ & $0.99(0.63)$ \\
\hline IgM Anti-PC, U/ml & $60.9(36.4-94.9)$ \\
\hline \multicolumn{2}{|l|}{ At 1 year } \\
\hline DAS28 remission, \% & 36.3 \\
\hline Use of MTX the first year, \% & 50 \\
\hline Use of glucocorticosteroids the first year, \% & 51 \\
\hline \multicolumn{2}{|l|}{ At 2 years } \\
\hline DAS28 remission, \% & 39.5 \\
\hline Use of MTX first 2 years, $\%$ & 58 \\
\hline Use of glucocorticosteroids first 2 years, $\%$ & 53 \\
\hline Use of biological first 2 years, $\%$ & 2.4 \\
\hline IgM Anti-PC, U/ml & $56.0(32.4-84.2)$ \\
\hline IgM Anti-PC AUC per 2 years, U/ml & $117.3(68.8-201.4)$ \\
\hline
\end{tabular}

Values are reported as mean (SD), median (IQR), or percentage $B M I$, body mass index; Seropositive, RF and/or ACPA positive; DAS28, Disease Activity Score 28-joint count; DAS28 remission, if DAS28 < 2.6; HAQ, Health Assessment Questionnaire; Anti-PC, phosphorylcholine autoantibodies; MTX, methotrexate 
years old at inclusion, in males, in patients with BMI above $30 \mathrm{~kg} / \mathrm{m}^{2}$, and in those with hypertension (Table 2).

During an 11.7-year mean follow-up, the patients experienced 141 first CVE (21.6\%), corresponding to an incidence rate of 1.85 events per 100 person-years $(95 \% \mathrm{CI}$, 1.54-2.15). Of these, ischemic coronary events were censored in 73 cases, ischemic cerebrovascular events in 49, and both coronary and cerebrovascular events in 19 cases.

\section{Outcome of incident CV events in relation to IgM anti-PC}

First, the association between autoantibodies IgM antiPC and CV outcome was studied. This analysis showed that event-free times were significantly better among patients with the baseline levels of IgM anti-PC above median compared with those below median, $p=0.003$ by the log-rank test (Fig. 1). The higher levels of IgM antiPC were associated with a $40 \%$ reduction in CV risk, HR 0.603 (95\% CI, 0.430-0.846) (Table 3).

We hypothesized that the association between IgM anti-PC and the risk of $\mathrm{CV}$ outcome is different in the presence of $\mathrm{CV}$ risk factors. We therefore further performed analyses within the groups categorized by risk factors (Table 3). In unadjusted survival analyses, the risk of $\mathrm{CV}$ was lower in patients with the baseline levels of IgM anti-PC above median in those aged below 55 years, of both sexes, BMI below $25 \mathrm{~kg} / \mathrm{m}^{2}$ and above 30 $\mathrm{kg} / \mathrm{m}^{2}$, without traditional risk factors (non-smokers, non-hypertensives, non-hyperlipidemic), seronegative, and among those who did not achieve DAS28 remission at 1-year and 2-year follow-up. In multivariate analyses, baseline IgM anti-PC above median was significantly associated with decreased risk of $\mathrm{CV}$ outcome in patients aged below 55 years at inclusion, HR 0.360 (95\% CI, 0.142-0.916); in males, HR 0.558 (95\% CI, 0.325-0.958); in those with BMI above $30 \mathrm{~kg} / \mathrm{m}^{2}$, HR 0.235 (95\% CI, $0.065-0.842)$; and among those who did not achieve DAS28 remission at 1 year, HR $0.592(95 \%$ CI, 0.379 0.924) (Table 3, Fig. 2).

Similarly, applying the integrated measurement of IgM anti-PC over 2 years, the higher levels above median of

Table 2 IgM anti-PC autoantibody baseline distribution (median) according to characteristics of patients with rheumatoid arthritis

\begin{tabular}{|c|c|c|c|c|}
\hline & & \multicolumn{3}{|c|}{ IgM anti-PC, $\mathrm{U} / \mathrm{ml}$, baseline distribution } \\
\hline & & $\bar{n}$ & Median & $p$ value \\
\hline \multirow[t]{2}{*}{ CV events during follow-up } & Non-CV & 512 & 64.19 & 0.020 \\
\hline & CV & 141 & 51.79 & \\
\hline \multirow[t]{2}{*}{ Age, years } & $<55$ & 317 & 69.21 & $<0.001$ \\
\hline & $>55$ & 336 & 53.20 & \\
\hline \multirow[t]{2}{*}{ Sex } & Female & 443 & 64.81 & $<0.001$ \\
\hline & Male & 210 & 52.90 & \\
\hline \multirow[t]{3}{*}{$\mathrm{BMl}, \mathrm{kg} / \mathrm{m}^{2}$} & $<25$ & 334 & 67.28 & 0.002 \\
\hline & $25-30$ & 235 & 55.02 & \\
\hline & $>30$ & 84 & 47.56 & \\
\hline \multirow[t]{2}{*}{ Smoking } & Non-smoker & 463 & 58.34 & 0.070 \\
\hline & Current smoker & 190 & 65.0 & \\
\hline \multirow[t]{2}{*}{ Hypertension } & Non-hypertensive & 554 & 62.68 & 0.013 \\
\hline & Hypertensive & 99 & 47.91 & \\
\hline \multirow[t]{2}{*}{ Diabetes mellitus } & Non-diabetic & 627 & 60.89 & 0.631 \\
\hline & Diabetic & 26 & 56.98 & \\
\hline \multirow[t]{2}{*}{ Hyperlipidemia } & Non-hyperlipidemic & 648 & 60.88 & 0.658 \\
\hline & Hyperlipidemic & 5 & 48.17 & \\
\hline \multirow[t]{2}{*}{ Seropositive } & Seropositive & 441 & 63.59 & 0.190 \\
\hline & Seronegative & 212 & 55.35 & \\
\hline \multirow[t]{2}{*}{ DAS28 remission at 1 year } & Remission & 237 & 61.11 & 0.895 \\
\hline & Non-remission & 416 & 60.10 & \\
\hline \multirow[t]{2}{*}{ DAS28 remission at 2 years } & Remission & 256 & 61.73 & 0.223 \\
\hline & Non-remission & 397 & 57.97 & \\
\hline
\end{tabular}

Statistical significance was tested with the Mann-Whitney $U$ test $B M I$, body mass index; DAS28, Disease Activity Score 28-joint count; DAS28 remission, if DAS28 < 2.6; HAQ, Health Assessment Questionnaire; Anti-PC, phosphorylcholine antibodies 


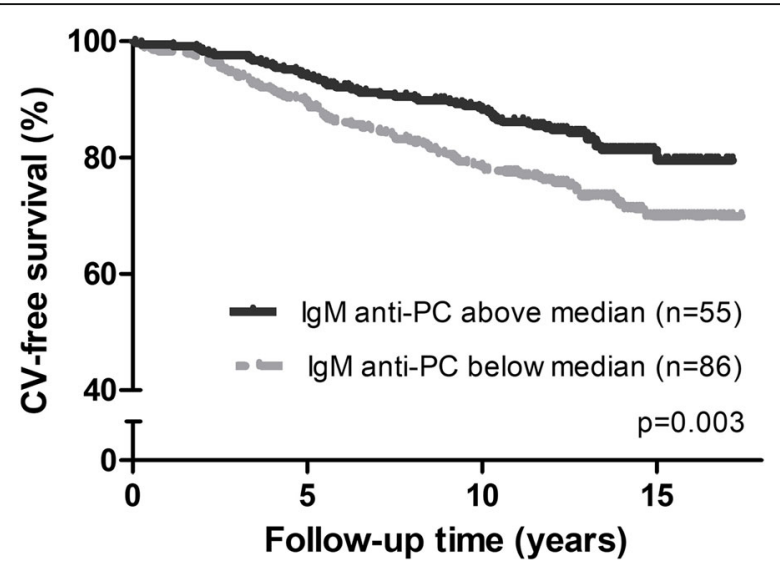

Fig. 1 Kaplan-Meier estimates of CV-free survival in rheumatoid arthritis according to baseline IgM anti-PC levels. Kaplan-Meier curves in the total cohort, $p$ values by log-rank test, and number ( $n$ ) of CV outcomes recorded in the groups categorized by baseline lgM anti-PC levels above and below median

AUC IgM anti-PC were associated with reduced CV risk, HR 0.614 (95\% CI, 0.423-0.890). The levels above median of AUC IgM anti-PC were independently associated with a CV risk reduction in males, HR 0.428 (95\% CI, $0.227-0.807)$, and in patients with BMI above $30 \mathrm{~kg} / \mathrm{m}^{2}$, HR 0.297 (95\% CI, 0.089-0.988). Likely because of lower numbers in analysis and a shorter observation period, the association between the higher AUC IgM anti-PC and a better CV outcome was attenuated in patients not in DAS28 remission, adjusted HR 0.648 (95\% CI, 0.3951.064) (Table 3). This pattern of associations in males, in patients with a higher BMI, and among those not in DAS28 remission the first 2 years was confirmed in the models with IgM anti-PC measurement at 2-year followup (data not shown).

\section{Discussion}

In this study in patients with early RA, we observed that higher levels of IgM anti-PC autoantibodies, compared with lower levels, were associated with fewer incident CVE over more than 10 years. The benefits of higher IgM anti-PC levels for the reduction of $\mathrm{CV}$ risk were shown in younger patients, in males, and in the presence of obesity and if DAS28 remission was not achieved after 1 year. These findings suggest that the protective function of innate immunity could be primarily detected in patients at high risk of CVE. This points out to an alternative pathway in atherothrombosis which may be activated in the presence of additional pro-inflammatory factors, thus intersecting with traditional pathways.

A large body of evidence supports a role for chronic inflammation in atherogenesis, and autoantibodies have been identified as mediators in the complex inflammatory environment. The concept of autoimmune diseases suggests that autoantibodies are inherently pathogenic; however, some autoantibodies of innate "natural" immunity are protective, i.e., "protective autoimmunity." Innate IgM autoantibodies could arise spontaneously without antigenic or microbial stimuli. These IgM autoantibodies are present in the circulation from birth [28], and they are also developed by exposure to the phospholipids, such as phosphorylcholine (PC) [29]. PC is present in apoptotic cells, and they act as enhancers of the inflammation underlying both atherosclerosis and autoimmunity [30, 31]. IgM anti-PC antibodies recognizing and increasing the clearance of dying cells have been postulated as regulators of the inflammatory pathways possibly driving immunosenescence and atherogenesis [22, 32].

We here confirmed and extended the previous findings of lower levels of IgM anti-PC autoantibodies in men compared to women, and higher levels of these autoantibodies in younger patients compared to older ones [13,14,21]. An interesting question is whether atherosclerosis should be seen as a normal part of human aging or as a pathological process which could be, if not abolished, at least strongly reduced. The underlying mechanisms that cause decreased IgM anti-PC levels could have different explanations including both lifestyle factors, differences in diet, exposure to infections, and underlying genetic variations. However, both among New Guineans with a traditional lifestyle and in Swedish controls with a western lifestyle, men had significantly lower levels of IgM anti-PC as compared to women [33]. It thus appears that low levels of IgM anti-PC are likely a part of predisposition for atherosclerosis in males. Genetic factors could also play an additional role since the heritability of anti-PC is 37\% [34]. Given the biological role of IgM anti-PC in modulation and antiatherogenic mechanisms, it is tempting to hypothesize that high levels of anti-PC may slow down the progression of atherosclerosis and may facilitate the stabilization of plaque. Indeed, the lower levels of IgM anti-PC have been demonstrated in patients with SLE in the presence of carotid atherosclerotic plaques [16] and also in individuals with the fastest progression of cIMT and carotid plaque measurements [14].

In addition, our data showed an association between higher levels of IgM anti-PC autoantibodies and risk reduction of CVE in men and younger patients with early RA. The findings here consistent with previous studies showing a sex difference in the risk of CVE associated with IgM anti-PC antibodies [13, 14]. Both in the current analysis and an earlier large epidemiological study [13], the association between IgM anti-PC and risk of CVE was not affected by the presence of traditional risk factors, suggesting that activation of innate immunity pathway might be independent of traditional 
Table 3 Association between IgM anti-PC and incident CVE, in total and within groups by risk characteristics

\begin{tabular}{|c|c|c|c|c|c|}
\hline & $N$ of events & $\begin{array}{l}\text { Non-adjusted } \\
\text { HR }(95 \% \mathrm{Cl})\end{array}$ & $p$ & $\begin{array}{l}\text { Adjusted } \\
\text { HR }(95 \% \mathrm{Cl})\end{array}$ & $p$ \\
\hline $\begin{array}{l}\text { IgM anti-PC baseline } \\
>\text { median vs. }<\text { median }\end{array}$ & 141 & $0.603(0.430-0.846)$ & 0.003 & $0.828(0.589-1.165)$ & 0.279 \\
\hline \multicolumn{6}{|l|}{ Analyses within strata } \\
\hline \multicolumn{6}{|l|}{ Age } \\
\hline Age $<55$ years & 22 & $0.396(0.166-0.943)$ & 0.036 & $0.360(0.142-0.916) \dagger$ & 0.032 \\
\hline Age $>55$ years & 119 & $0.883(0.611-1.277)$ & 0.510 & - & \\
\hline \multicolumn{6}{|l|}{ Sex } \\
\hline Women & 81 & $0.608(0.391-0.945)$ & 0.027 & $0.985(0.629-1.541)$ & 0.946 \\
\hline Men & 60 & $0.614(0.359-1.050)$ & 0.075 & $0.558(0.325-0.958) \dagger$ & 0.034 \\
\hline \multicolumn{6}{|l|}{ BMI } \\
\hline $\mathrm{BMl}<25 \mathrm{~kg} / \mathrm{m}^{2}$ & 63 & $0.524(0.316-0.868)$ & 0.012 & $0.827(0.496-1.377)$ & 0.465 \\
\hline BMI $25-30 \mathrm{~kg} / \mathrm{m}^{2}$ & 59 & $0.885(0.523-1.498)$ & 0.650 & - & \\
\hline $\mathrm{BMI}>30 \mathrm{~kg} / \mathrm{m}^{2}$ & 19 & $0.278(0.080-0.969)$ & 0.044 & $0.235(0.065-0.842) \dagger$ & 0.026 \\
\hline \multicolumn{6}{|l|}{ Smoking } \\
\hline Non-smoker & 98 & $0.510(0.337-0.774)$ & 0.002 & $0.722(0.475-1.098)$ & 0.128 \\
\hline Current smoker & 43 & $0.877(0.482-1.597)$ & 0.668 & - & \\
\hline \multicolumn{6}{|l|}{ Hypertension } \\
\hline Non-hypertensive & 104 & $0.594(0.402-0.880)$ & 0.009 & $0.878(0.591-1.305)$ & 0.520 \\
\hline Hypertensive & 37 & $0.805(0.410-1.583)$ & 0.530 & - & \\
\hline \multicolumn{6}{|l|}{ Diabetes mellitus } \\
\hline Non-diabetic & 133 & $0.663(0.469-0.936)$ & 0.019 & $0.899(0.635-1.273)$ & 0.549 \\
\hline Diabetic & 8 & $0.017(0.001-5.059)$ & 0.161 & - & \\
\hline \multicolumn{6}{|l|}{ Hyperlipidemia } \\
\hline Non-hyperlipidemic & 3 & $0.601(0.427-0.847)$ & 0.004 & $0.836(0.592-1.179)$ & 0.307 \\
\hline Hyperlipidemic & 138 & $1.423(0.126-16.043)$ & 0.775 & - & \\
\hline \multicolumn{6}{|l|}{ Seropositivity } \\
\hline Seropositive & 94 & $0.669(0.444-1.007)$ & 0.054 & $0.846(0.561-1.276)$ & 0.425 \\
\hline Seronegative & 47 & $0.496(0.265-0.927)$ & 0.028 & $0.782(0.415-1.473)$ & 0.782 \\
\hline \multicolumn{6}{|l|}{ DAS28 remission at 1 year } \\
\hline Remission & 49 & $1.235(0.691-2.206)$ & 0.476 & - & \\
\hline Non-remission & 92 & $0.440(0.284-0.683)$ & $<0.001$ & $0.592(0.379-0.924) \dagger$ & 0.021 \\
\hline \multicolumn{6}{|l|}{ DAS28 remission at 2 years } \\
\hline Remission & 54 & $0.851(0.498-1.457)$ & 0.557 & - & \\
\hline Non-remission & 87 & $0.498(0.320-0.774)$ & 0.002 & $0.681(0.435-1.068) \dagger$ & 0.095 \\
\hline $\begin{array}{l}\text { AUC of IgM anti-PC at baseline } \\
\text { and } 2 \text { years } \\
>\text { median vs. }<\text { median }\end{array}$ & 116 & $0.614(0.423-0.890)$ & 0.010 & $0.847(0.583-1.232)$ & 0.386 \\
\hline \multicolumn{6}{|l|}{ Age } \\
\hline Age $<55$ years & 16 & $0.520(0.194-1.397)$ & 0.195 & - & \\
\hline Age $>55$ years & 100 & $0.841(0.562-1.257)$ & 0.398 & - & \\
\hline \multicolumn{6}{|l|}{ Sex } \\
\hline Women & 67 & $0.765(0.474-1.236)$ & 0.274 & - & \\
\hline Men & 49 & $0.490(0.264-0.911)$ & 0.024 & $0.428(0.227-0.807) \dagger$ & 0.009 \\
\hline
\end{tabular}


Table 3 Association between IgM anti-PC and incident CVE, in total and within groups by risk characteristics (Continued)

\begin{tabular}{|c|c|c|c|c|c|}
\hline & $N$ of events & $\begin{array}{l}\text { Non-adjusted } \\
\text { HR }(95 \% \mathrm{Cl})\end{array}$ & $p$ & $\begin{array}{l}\text { Adjusted } \\
\text { HR }(95 \% \mathrm{Cl})\end{array}$ & $p$ \\
\hline \multicolumn{6}{|l|}{ BMI } \\
\hline $\mathrm{BMI}<25 \mathrm{~kg} / \mathrm{m}^{2}$ & 50 & $0.493(0.279-0.871)$ & 0.015 & $0.841(0.471-1.503)$ & 0.559 \\
\hline BMI $25-30 \mathrm{~kg} / \mathrm{m}^{2}$ & 48 & $0.973(0.547-1.730)$ & 0.926 & - & \\
\hline $\mathrm{BMI}>30 \mathrm{~kg} / \mathrm{m}^{2}$ & 18 & $0.330(0.105-1.031)$ & 0.056 & $0.297(0.089-0.988) \dagger$ & 0.048 \\
\hline \multicolumn{6}{|c|}{ DAS28 remission at 1 year } \\
\hline Remission & 40 & $1.121(0.591-2,124)$ & 0.727 & - & \\
\hline Non-remission & 76 & $0.487(0.300-0.791)$ & 0.004 & $0.648(0.395-1.064) \dagger$ & 0.087 \\
\hline \multicolumn{6}{|c|}{ DAS28 remission at 2 years } \\
\hline Remission & 44 & $0.856(0.473-1.549)$ & 0.607 & - & \\
\hline Non-remission & 72 & $0.510(0.314-0.828)$ & 0.006 & $0.698(0.430-1.136)$ & 0.148 \\
\hline
\end{tabular}

Values are hazard ratios (HRs) with $95 \% \mathrm{Cl}$ obtained with Cox proportional hazard regression. The number of patients with measures of IgM anti-PC at baseline was 653 , and the number of patients with measures of AUC of IgM anti-PC was 523 . Anti-PC baseline median $\geq 60.9 \mathrm{U} / \mathrm{ml}, \mathrm{AUC}$ of anti-PC median $\geq 117.3 \mathrm{U} / \mathrm{ml}$ CVE, cardiovascular events; BMI, body mass index; DAS28, Disease Activity Score 28-joint count; DAS28 remission, if DAS28 < 2.6; HAQ, Health Assessment Questionnaire; Anti-PC, phosphorylcholine antibodies

Adjusted for age and sex. THR, a fully adjusted (for age, sex, BMl, smoking, hypertension, diabetes mellitus, hyperlipidemia) analysis was run if results of the analyses adjusted for age and sex showed a $p<0.10$

pathways. Meanwhile, IgM anti-PC autoantibodies may be of particular interest for risk stratification in some patient groups, such as at younger ages. The reduction of $\mathrm{CV}$ risk in younger patients in association with higher levels of IgM anti-PC autoantibodies reported herein might reflect the age-related variation in plaque composition and plaque remodeling mechanisms at different ages [35]. In line with here reported findings, both the faster progression of carotid atherosclerosis and the higher risk of CVE in association with low anti-PC levels have been shown in younger individuals, whereas this association was not found in the older ones [14]. It thus
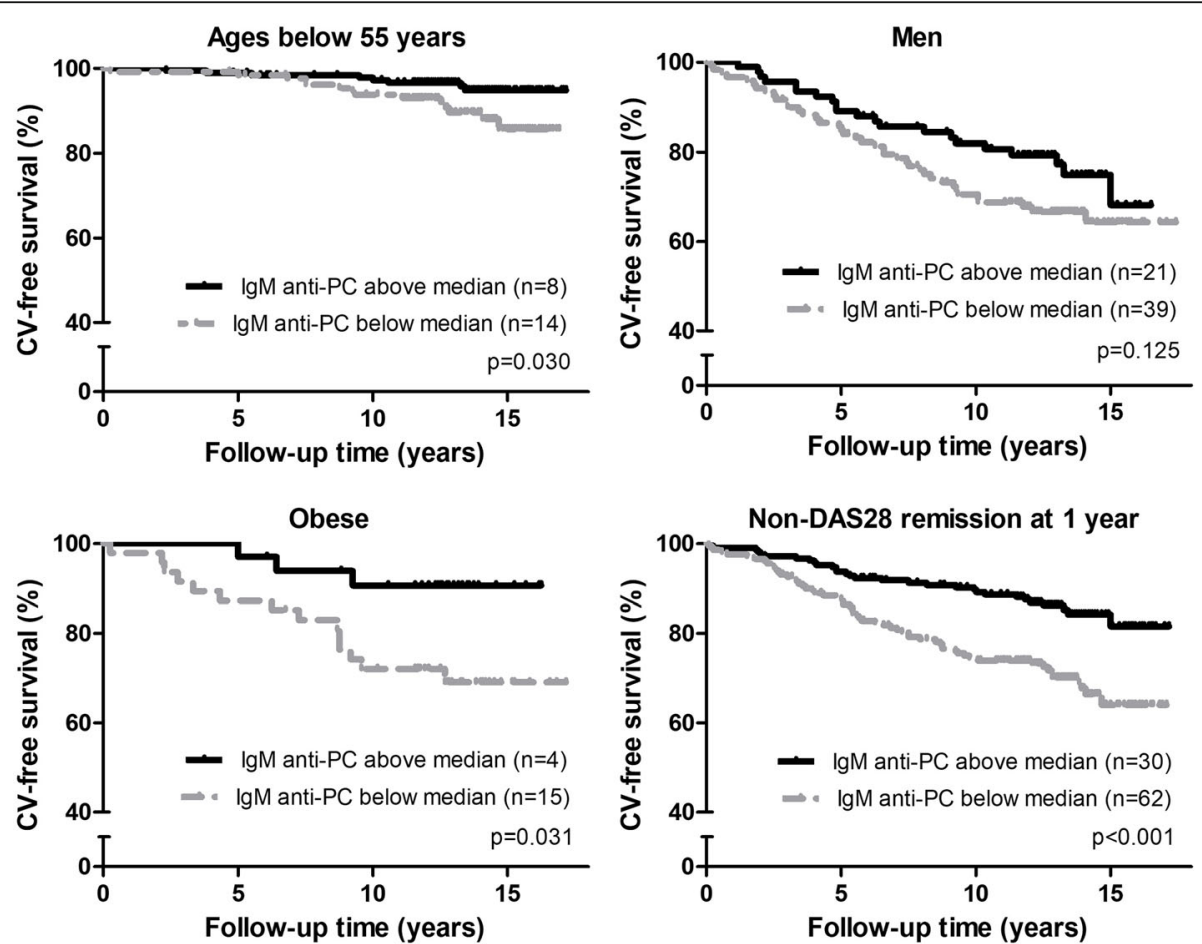

Fig. 2 Kaplan-Meier estimates of CV-free survival within the patient groups as indicated. Kaplan-Meier curves within the patients with rheumatoid arthritis aged below 55 years at inclusion, men, obese, and in those who did not achieve DAS28 remission at 1-year follow-up, $p$ values by logrank test, and number $(n)$ of CV outcomes recorded in the groups categorized by baseline IgM anti-PC levels above and below the median 
seems that low levels of IgM anti-PC could be a part of human senescence. Also, in the study on individuals from New Guinea, IgM anti-PC was lower in New Guineans over the age of 40 compared to those under 40 years old and decreased with age among Swedish controls above 40 years old [33]. Although the results from these studies cannot provide definitive answers for a sex and age difference in the risk of CVE associated with IgM anti-PC antibodies, it is possible that innate immunity state could be one of the underlying factors of the known lower risk of CVD in women as compared to men of similar age and in younger individuals compared to older ones.

The underlying mechanism by which the protective innate immunity pathway could be activated is not clear. One of the explanations could be a direct effect on the endothelium, which could become dysfunctional as a response to injury, such as oxidative stress, leading to pro-inflammatory immunogenic effects. IgM anti-PC and other phospholipids could have dual immunomodulatory effects: they might be protective by neutralizing the inflammatory effects by initiation and progression of atherosclerosis, as well as ensuing plaque rupture, while low levels of these autoantibodies could be per se a cause of inflammation in the context of oxidative stress [4]. The protective effect of some gene polymorphisms on the risk of atherosclerotic disease has been reported in anti-CCP-negative patients with RA [36, 37]. Interestingly, in unadjusted analysis herein, the higher levels of IgM anti-PC were associated with a reduction of $\mathrm{CV}$ risk in the group of anti-CCP-negative patients. Whether IgM anti-PC antibodies may be a part of the explanation of lower CV risk in seronegative RA and whether genetic determinants and epigenetic modifications are involved in the activation of the atheroprotective function of these antibodies are not known.

In this analysis, levels of IgM anti-PC antibodies were lower in patients with BMI above $30 \mathrm{~kg} / \mathrm{m}^{2}$, which is consistent with previous reports in SLE patients [38]. Obesity is associated with an increased risk of metabolic syndrome and CVE within most westernized populations, but it also seems that fat distribution, lean mass, and cardio fitness, i.e., adiposity and cachexia, could play an essential role in determining morbidity. Abundant data indicate the presence of increased pro-inflammatory adipose tissue macrophages, as well as other immune cells, and decreased number, or proportion, of adipose tissue Treg cells, in obesity [39], which, in turn, could cause inflammation and contributes critically to atherothrombosis. Innate immunity may play an additional role in modulating metabolic and pro-inflammatory consequences in obesity, i.e., immunometabolism. Even though it remains to be shown, it is possible that direct and indirect effects of adiposity on inflammatory cells could induce a hypoxic state promoting inflammation and endothelial dysfunction. In the clinical setting, the levels of anti-PC IgM were lower in patients with rheumatoid cachexia than in those without [40]. Interestingly, no correlation has been observed between levels of IgM anti-PC, LDL cholesterol, HDL cholesterol, and hsCRP [14], in line with an earlier report of an independent association between low IgM anti-PC and bilateral carotid plaque in patients with RA [41]. Altogether, it suggests an alternative pathway of atheroprotective effects of IgM anti-PC, independent of the traditional hyperlipidemic pathway.

The data presented herein showed a reduction of $\mathrm{CV}$ risk in association with high levels of IgM anti-PC in patients with BMI above $30 \mathrm{~kg} / \mathrm{m}^{2}$, suggesting high levels of innate autoantibodies as a protective factor in obesity. An important provisional hypothesis deriving from the current analysis is that high levels of IgM anti-PC autoantibodies could "compete out" CVE risk, at least to some extent, in obese patients through the protective innate immunity pathway. Importantly, diet and physical activity may influence IgM anti-PC in RA. The dietary studies have reported the very high levels of anti-PC in patients with RA on a Mediterranean diet, increased levels of anti-PC when changing from a Western diet to a gluten-free vegan diet [40,42], and also low levels of IgM anti-PC in association with low physical activity [43]. Given the atheroprotective effects of higher levels of IgM anti-PC, lifestyle and physical activity recommendations should be encouraged.

Finally, the intriguing finding of this study is that higher levels of IgM anti-PC autoantibodies were protective in patients who were not in DAS28 remission at 1-year follow-up. This observation is likely consistent with the oxidative stress hypothesis of activation of protective innate immunity pathway, a means for the host to survive in a setting of chronic inflammation [30]. It has long been stated that both RA and atherosclerosis share similar underlying inflammatory pathways [3]. Disease activity is one of the contributing risk factors for increased atherosclerosis and CVD in patients with RA. Tight-control treatment and additional benefits of sustained disease remission, as compared to low disease activity, are associated with normalized survival in patients with RA [44].

Although herein we could not detect differences in the distribution of IgM anti-PC autoantibodies by disease activity among patients with early RA, in the previous cross-sectional study of established RA, patients with DAS28 remission after 12 months, compared to those not in remission, had higher baseline anti-PC levels [45]. These findings complement previous work in which low levels of IgM anti-PC autoantibodies have been demonstrated in patients with RA who experienced a subsequent CVE [15]. The studies in SLE have shown a 
correlation between increased levels of IgM and a lower disease activity along with damage scores, the reduced presence of carotid artery plaques, and reduced frequency of CVE $[16,46]$. Low IgM anti-PC levels may characterize an immunodeficiency and chronic inflammation not captured by conventional laboratory methods [45]. Indeed, a previous study has found that IgM anti-PC autoantibodies significantly increased during 1-year anti-TNF treatment in patients with RA, possibly through a direct inhibitory effect of TNF on B-cells producing anti-PC, or indirectly through decreased systemic inflammation [45]. Immunomodulatory drugs, such as methotrexate and anti-TNF treatments, have been associated with improved endothelial function and CV outcome in RA $[47,48]$. In this context, an interesting therapeutic question is whether amelioration of autoimmunity could also ameliorate atherosclerosis. Immunization with a vaccine containing PC could have provided proof of principle that an alternative innate immunity pathway can prevent atherosclerotic events.

Although we cannot provide direct evidence of drug effects in this study, DAS28 remission could likely give an estimation of conventional treatment effects in the patient cohort sampled before a broad use of biologicals. Because of the small numbers of patients in the subgroups, relevant effects of IgM anti-PC in the presence of some risk factors may not have been detected. At the same time, the strength of the study is its sample size and prospective design with long-term follow-up sufficient to study CV outcomes.

\section{Conclusion}

Our data suggest the benefits of higher levels of innate IgM anti-PC autoantibodies in the reduction of $\mathrm{CV}$ risk in early RA, in particular in younger patients and in those at high risk of CVE. This study supports the novel hypothesis of "protective autoimmunity" and emphasizes the potential value of an alternative innate antiinflammatory mechanism in atheroprotection and chronic inflammation, which might be activated in the presence of additional pro-inflammatory factors. We believe that closer investigation into the underlying mechanisms by which innate immunity protects against the risk of CVE represents an important evolving area that may have diagnostic and therapeutic implications beyond rheumatology.

\footnotetext{
Abbreviations

ACR: American College of Rheumatology; Anti-CCP: Antibodies to cyclic citrullinated peptides; Anti-PC: Anti-phosphorylcholine autoantibodies; AUC: Area under the curve; BARFOT: Better Anti-Rheumatic PharmacO Therapy; BMI: Body mass index; Cl: Confidence interval; cIMT: Carotid intimamedia thickness; CRP: C-reactive protein; CV: Cardiovascular; CVD: Cardiovascular disease; CVE: Cardiovascular events; DAS28: Disease Activity Score for 28 joints; DMARD: Disease-modifying anti-rheumatic drug; ELISA: Enzyme-linked immunosorbent assay; ESR: Erythrocyte sedimentation rate; HAQ: Health Assessment Questionnaire; HDL: High-density lipoprotein; HR: Hazard ratio; IQR: Interquartile range; LDL: Low-density lipoprotein;
}

MTX: Methotrexate; PC: Phosphorylcholine; RA: Rheumatoid arthritis; RF: Rheumatoid factor; SD: Standard deviation; SLE: Systemic lupus erythematosus; TIA: Transient ischemic attack

\section{Acknowledgements}

We thank research nurse Margareta Wörnert for her expert assistance with blood sampling, and all members of the BARFOT study group.

\section{Authors' contributions}

$\mathrm{SA}, \mathrm{JF}$, and $\mathrm{IH}$ designed the study. SA, MA, and $\mathrm{H}$ were responsible for the data collection. SA performed the data analyses and drafted the manuscript. All authors contributed to the interpretation of the data and approved the final manuscript.

\section{Funding}

This work was supported by grants from The Swedish Rheumatism Association, King Gustav V 80 year's Foundation, The Swedish Heart-Lung

Foundation. Open Access funding provided by Karolinska Institute.

Availability of data and materials

All data relevant to the study are included in the article.

\section{Declarations}

Ethics approval and consent to participate

The study was approved by the local ethics committees, EPN Stockholm 2008/840-31 and 2011/381-31/4. The study participants provided written informed consent.

\section{Consent for publication}

Not required.

\section{Competing interests}

J.F. is named as an inventor on patents of anti-PC.

\section{Author details}

${ }^{1}$ Division of Gastroenterology and Rheumatology, Department of Medicine Huddinge, Karolinska Institutet, 17177 Stockholm, Sweden. ${ }^{2}$ Department of Clinical Sciences, Rheumatology Division, Universitair Ziekenhuis Brussel, Vrije Universiteit Brussel, Brussels, Belgium. ${ }^{3}$ Faculty of Medicine, Department of Rheumatology, Lund University, Lund and Spenshult Research and Development Centre, Halmstad, Sweden. ${ }^{4}$ Section of Immunology and Chronic disease, Institute of Environmental Medicine, Karolinska Institutet, Stockholm, Sweden. ${ }^{5}$ Rheumatology Unit, Karolinska University Hospital, Stockholm, Sweden.

Received: 4 May 2021 Accepted: 15 July 2021

Published online: 27 July 2021

\section{References}

1. Arts EE, Popa C, Den Broeder AA, Semb AG, Toms T, Kitas GD, et al. Performance of four current risk algorithms in predicting cardiovascular events in patients with early rheumatoid arthritis. Ann Rheum Dis. 2015; 74(4):668-74. https://doi.org/10.1136/annrheumdis-2013-204024.

2. Lopez-Mejias R, Castaneda S, Gonzalez-Juanatey C, Corrales A, Ferraz-Amaro I, Genre F, et al. Cardiovascular risk assessment in patients with rheumatoid arthritis: the relevance of clinical, genetic and serological markers. Autoimmun Rev. 2016;15(11):1013-30. https://doi.org/10.1016/j.autrev.2016. 07.026.

3. Libby P, Ridker PM, Hansson GK, Leducq Transatlantic Network on A. Inflammation in atherosclerosis: from pathophysiology to practice. J Am Coll Cardiol. 2009;54(23):2129-38. https://doi.org/10.1016/j.jacc.2009.09.009.

4. Frostegard J. Immunity, atherosclerosis and cardiovascular disease. BMC Med. 2013;11(1):117. https://doi.org/10.1186/1741-7015-11-117.

5. Iseme RA, McEvoy M, Kelly B, Agnew L, Walker FR, Handley T, et al. A role for autoantibodies in atherogenesis. Cardiovasc Res. 2017;113(10):1102-12. https://doi.org/10.1093/cvr/cvx112.

6. Chou MY, Hartvigsen K, Hansen LF, Fogelstrand L, Shaw PX, Boullier A, et al. Oxidation-specific epitopes are important targets of innate immunity. J Intern Med. 2008;263(5):479-88. https://doi.org/10.1111/j.13 65-2796.2008.01968.x 
7. Sun J, Lundstrom SL, Zhang B, Zubarev RA, Steuer J, Gillgren P, et al. IgM antibodies against phosphorylcholine promote polarization of $\mathrm{T}$ regulatory cells from patients with atherosclerotic plaques, systemic lupus erythematosus and healthy donors. Atherosclerosis. 2018;268:36-48. https:// doi.org/10.1016/j.atherosclerosis.2017.11.010.

8. Shaw PX, Horkko S, Chang MK, Curtiss LK, Palinski W, Silverman GJ, et al. Natural antibodies with the T15 idiotype may act in atherosclerosis, apoptotic clearance, and protective immunity. J Clin Invest. 2000;105(12): 1731-40. https://doi.org/10.1172/JCl8472.

9. Silverman GJ. Protective natural autoantibodies to apoptotic cells: evidence of convergent selection of recurrent innate-like clones. Ann N Y Acad Sci. 2015;1362(1):164-75. https://doi.org/10.1111/nyas.12788.

10. Frostegard J. Low level natural antibodies against phosphorylcholine: a novel risk marker and potential mechanism in atherosclerosis and cardiovascular disease. Clin Immunol. 2010;134(1):47-54. https://doi.org/10.1 016/j.clim.2009.08.013.

11. Gronlund $H$, Hallmans $G$, Jansson JH, Boman K, Wikstrom M, de Faire U, et al. Low levels of IgM antibodies against phosphorylcholine predict development of acute myocardial infarction in a population-based cohort from northern Sweden. Eur J Cardiovasc Prev Rehabil. 2009;16(3):382-6. https://doi.org/10.1097/HJR.0b013e32832a05df

12. Sjoberg BG, Su J, Dahlbom I, Gronlund H, Wikstrom M, Hedblad B, et al. Low levels of IgM antibodies against phosphorylcholine-a potential risk marker for ischemic stroke in men. Atherosclerosis. 2009;203(2):528-32. https://doi. org/10.1016/j.atherosclerosis.2008.07.009.

13. de Faire U, Su J, Hua X, Frostegard A, Halldin M, Hellenius ML, et al. Low levels of IgM antibodies to phosphorylcholine predict cardiovascular disease in 60-year old men: effects on uptake of oxidized LDL in macrophages as a potential mechanism. J Autoimmun. 2010;34(2):73-9. https://doi.org/10.101 6/j.jaut.2009.05.003.

14. Gigante B, Leander K, Vikstrom M, Baldassarre D, Veglia F, Strawbridge RJ, et al. Low levels of IgM antibodies against phosphorylcholine are associated with fast carotid intima media thickness progression and cardiovascular risk in men. Atherosclerosis. 2014;236(2):394-9. https://doi.org/10.1016/j.a therosclerosis.2014.07.030.

15. Ajeganova S, de Faire U, Jogestrand T, Frostegard J, Hafstrom I. Carotid atherosclerosis, disease measures, oxidized low-density lipoproteins, and atheroprotective natural antibodies for cardiovascular disease in early rheumatoid arthritis -- an inception cohort study. J Rheumatol. 2012;39(6): 1146-54. https://doi.org/10.3899/jrheum.111334.

16. Anania C, Gustafsson T, Hua X, Su J, Vikstrom M, de Faire U, et al. Increased prevalence of vulnerable atherosclerotic plaques and low levels of natural IgM antibodies against phosphorylcholine in patients with systemic lupus erythematosus. Arthritis Res Ther. 2010;12(6):R214. https://doi.org/10.1186/a r3193.

17. Fiskesund R, Su J, Bulatovic I, Vikstrom M, de Faire U, Frostegard J. IgM phosphorylcholine antibodies inhibit cell death and constitute a strong protection marker for atherosclerosis development, particularly in combination with other auto-antibodies against modified LDL. Results Immunol. 2012;2:13-8. https://doi.org/10.1016/j.rinim.2012.01.001.

18. Rahman M, Sing S, Golabkesh Z, Fiskesund R, Gustafsson T, Jogestrand T, et al. IgM antibodies against malondialdehyde and phosphorylcholine are together strong protection markers for atherosclerosis in systemic lupus erythematosus: regulation and underlying mechanisms. Clin Immunol. 2016; 166-167:27-37.

19. Imhof A, Koenig W, Jaensch A, Mons U, Brenner H, Rothenbacher D. Long term prognostic value of IgM antibodies against phosphorylcholine for adverse cardiovascular events in patients with stable coronary heart disease. Atherosclerosis. 2015;243(2):414-20. https://doi.org/10.1016/j.a therosclerosis.2015.10.024

20. Geller BJ, Mega JL, Morrow DA, Guo J, Hoffman EB, Gibson CM, et al. Autoantibodies to phosphorylcholine and cardiovascular outcomes in patients with acute coronary syndromes in the ATLAS ACS-TIMI 46 trial. J Thromb Thrombolysis. 2014;37(3):310-6. https://doi.org/10.1007/s11239-0130968-y.

21. Su J, Georgiades A, Wu R, Thulin T, de Faire U, Frostegard J. Antibodies of IgM subclass to phosphorylcholine and oxidized LDL are protective factors for atherosclerosis in patients with hypertension. Atherosclerosis. 2006; 188(1):160-6. https://doi.org/10.1016/j.atherosclerosis.2005.10.017.

22. Lopez P, Rodriguez-Carrio J, Martinez-Zapico A, Perez-Alvarez Al, Benavente L, Caminal-Montero L, et al. IgM anti-phosphorylcholine antibodies associate with senescent and IL-17+ T cells in SLE patients with a pro-inflammatory lipid profile. Rheumatology (Oxford). 2020;59(2):407-17. https://doi.org/10.1 093/rheumatology/kez264

23. Arnett FC, Edworthy SM, Bloch DA, McShane DJ, Fries JF, Cooper NS, et al. The American Rheumatism Association 1987 revised criteria for the classification of rheumatoid arthritis. Arthritis Rheum. 1988;31(3):315-24. https://doi.org/10.1002/art.1780310302.

24. Hafstrom I, Ajeganova S, Andersson ML, Bala SV, Bergman S, Bremander A, et al. A Swedish register-based, long-term inception cohort study of patients with rheumatoid arthritis - results of clinical relevance. Open Access Rheumatol. 2019;11:207-17. https://doi.org/10.2147/OARRR.S218448.

25. Prevoo ML, van't Hof MA, Kuper HH, van Leeuwen MA, van de Putte LB, van Riel PL. Modified disease activity scores that include twenty-eight-joint counts. Development and validation in a prospective longitudinal study of patients with rheumatoid arthritis. Arthritis Rheum. 1995;38(1):44-8. https:// doi.org/10.1002/art.1780380107.

26. Prevoo ML, van Gestel AM, van T Hof MA, van Rijswijk MH, van de Putte LB, van Riel PL. Remission in a prospective study of patients with rheumatoid arthritis. American Rheumatism Association preliminary remission criteria in relation to the disease activity score. Br J Rheumatol. 1996;35(11):1101-5. https://doi.org/10.1093/rheumatology/35.11.1101.

27. Ekdahl C, Eberhardt K, Andersson SI, Svensson B. Assessing disability in patients with rheumatoid arthritis. Use of a Swedish version of the Stanford Health Assessment Questionnaire. Scand J Rheumatol. 1988;17(4):263-71. https://doi.org/10.3109/03009748809098795.

28. Thiagarajan D, Lundstrom SL, Pershagen G, Almqvist Malmros C, Andolf E, Hedman A, et al. Antibodies against phosphorylcholine and malondialdehyde during the first two years of life. J Immunol. 2020;205(8): 2109-16. https://doi.org/10.4049/jimmunol.2000437.

29. Frostegard J, Tao W, Rastam L, Lindblad U, Lindeberg S. Antibodies against phosphorylcholine among New Guineans compared to Swedes: an aspect of the hygiene/missing old friends hypothesis. Immunol Invest. 2017;46(1): 59-69. https://doi.org/10.1080/08820139.2016.1213279.

30. Gronwall C, Silverman GJ. Natural IgM: beneficial autoantibodies for the control of inflammatory and autoimmune disease. J Clin Immunol. 2014; 34(Suppl 1):S12-21.

31. Hartley A, Haskard D, Khamis R. Oxidized LDL and anti-oxidized LDL antibodies in atherosclerosis - novel insights and future directions in diagnosis and therapy<sup/>. Trends Cardiovasc Med. 2019;29(1):22-6. https://doi.org/10.1016/j.tcm.2018.05.010.

32. Gronwall C, Vas J, Silverman GJ. Protective roles of natural IgM antibodies. Front Immunol. 2012:3:66.

33. Frostegard J, Tao W, Georgiades A, Rastam L, Lindblad U, Lindeberg S. Atheroprotective natural anti-phosphorylcholine antibodies of lgM subclass are decreased in Swedish controls as compared to non-westernized individuals from New Guinea. Nutr Metab (Lond). 2007;4:7.

34. Rahman I, Atout R, Pedersen NL, de Faire U, Frostegard J, Ninio E, et al. Genetic and environmental regulation of inflammatory CVD biomarkers LpPLA2 and IgM anti-PC. Atherosclerosis. 2011;218(1):117-22. https://doi.org/1 0.1016/j.atherosclerosis.2011.04.038.

35. Pelisek J, Wendorff H, Wendorff C, Kuehnl A, Eckstein HH. Age-associated changes in human carotid atherosclerotic plaques. Ann Med. 2016;48(7): 541-51. https://doi.org/10.1080/07853890.2016.1204468.

36. Genre F, Lopez-Mejias R, Garcia-Bermudez M, Castaneda S, GonzalezJuanatey C, Llorca J, et al. Osteoprotegerin CGA haplotype protection against cerebrovascular complications in anti-CCP negative patients with rheumatoid arthritis. PLoS One. 2014;9(9):e106823. https://doi.org/10.1371/ journal.pone.0106823.

37. Garcia-Bermudez M, Lopez-Mejias R, Genre F, Castaneda S, GonzalezJuanatey C, Llorca J, et al. SMAD3 rs17228212 gene polymorphism is associated with reduced risk to cerebrovascular accidents and subclinical atherosclerosis in anti-CCP negative Spanish rheumatoid arthritis patients. PLoS One. 2013;8(10):e77695. https://doi.org/10.1371/journal.pone.0077695.

38. Lourdudoss C, Ajeganova S, Frostegard J. Association between dietary and metabolic factors and lgM antibodies to phosphorylcholine and malondialdehyde in patients with systemic lupus erythematosus and population-based matched controls. Clin Exp Rheumatol. 2018;36(3):428-33.

39. Lee YS, Olefsky J. Chronic tissue inflammation and metabolic disease. Genes Dev. 2021;35(5-6):307-28. https://doi.org/10.1101/gad.346312.120.

40. Elkan AC, Hakansson N, Frostegard J, Cederholm T, Hafstrom I. Rheumatoid cachexia is associated with dyslipidemia and low levels of atheroprotective 
natural antibodies against phosphorylcholine but not with dietary fat in patients with rheumatoid arthritis: a cross-sectional study. Arthritis Res Ther. 2009;11(2):R37. https://doi.org/10.1186/ar2643.

41. Ajeganova S, Ehrnfelt C, Alizadeh R, Rohani M, Jogestrand T, Hafstrom I, et al. Longitudinal levels of apolipoproteins and antibodies against phosphorylcholine are independently associated with carotid artery atherosclerosis 5 years after rheumatoid arthritis onset--a prospective cohort study. Rheumatology (Oxford). 2011;50(10):1785-93. https://doi.org/10.1093/ rheumatology/ker204.

42. Elkan AC, Sjoberg B, Kolsrud B, Ringertz B, Hafstrom I, Frostegard J. Glutenfree vegan diet induces decreased $L D L$ and oxidized LDL levels and raised atheroprotective natural antibodies against phosphorylcholine in patients with rheumatoid arthritis: a randomized study. Arthritis Res Ther. 2008;10(2): R34. https://doi.org/10.1186/ar2388.

43. Elkan AC, Hakansson N, Frostegard J, Hafstrom I. Low level of physical activity in women with rheumatoid arthritis is associated with cardiovascular risk factors but not with body fat mass--a cross sectional study. BMC Musculoskelet Disord. 2011;12(1):13. https://doi.org/10.1186/14 71-2474-12-13.

44. Ajeganova S, Huizinga T. Sustained remission in rheumatoid arthritis: latest evidence and clinical considerations. Ther Adv Musculoskelet Dis. 2017;9(10): 249-62. https://doi.org/10.1177/1759720X17720366.

45. Ajeganova S, Fiskesund R, de Faire U, Hafstrom I, Frostegard J. Effect of biological therapy on levels of atheroprotective antibodies against phosphorylcholine and apolipoproteins in rheumatoid arthritis - a one year study. Clin Exp Rheumatol. 2011:29(6):942-50.

46. Gronwall C, Akhter E, Oh C, Burlingame RW, Petri M, Silverman GJ. lgM autoantibodies to distinct apoptosis-associated antigens correlate with protection from cardiovascular events and renal disease in patients with SLE. Clin Immunol. 2012;142(3):390-8. https://doi.org/10.1016/j.clim.2012.01.002.

47. Deyab G, Hokstad I, Whist JE, Smastuen MC, Agewall S, Lyberg T, et al. Methotrexate and anti-tumor necrosis factor treatment improves endothelial function in patients with inflammatory arthritis. Arthritis Res Ther. 2017;19(1):232. https://doi.org/10.1186/s13075-017-1439-1.

48. Sepriano A, Kerschbaumer A, Smolen JS, van der Heijde D, Dougados M, van Vollenhoven R, et al. Safety of synthetic and biological DMARDs: a systematic literature review informing the 2019 update of the EULAR recommendations for the management of rheumatoid arthritis. Ann Rheum Dis. 2020;79(6):760-70. https://doi.org/10.1136/annrheumdis-2019-216653.

\section{Publisher's Note}

Springer Nature remains neutral with regard to jurisdictional claims in published maps and institutional affiliations.

Ready to submit your research? Choose BMC and benefit from:

- fast, convenient online submission

- thorough peer review by experienced researchers in your field

- rapid publication on acceptance

- support for research data, including large and complex data types

- gold Open Access which fosters wider collaboration and increased citations

- maximum visibility for your research: over $100 \mathrm{M}$ website views per year

At $\mathrm{BMC}$, research is always in progress.

Learn more biomedcentral.com/submissions 